\title{
Development of Nano Soy Milk through Sensory Attributes and Consumer Acceptability
}

\author{
Seyoung Ju ${ }^{1}$, Sooji Song ${ }^{1}$, Jeongnam Lee ${ }^{2}$, Sungwon Hwang ${ }^{3}$, Yoonmi Lee ${ }^{1}$, Yongseok Kwon ${ }^{4}$ (D) \\ and Yuyoung Lee ${ }^{5, *}$
}

1 Department of Integrated Biosiences, College of Biomedical and Health Science, Konkuk University, Chungju-si 27478, Korea; syoungju86@kku.ac.kr (S.J.); ssj4037@naver.com (S.S.); yoonmilee@kku.ac.kr (Y.L.)

2 Sahmyook Food R\&D Center, Seongin-ro, Cheonan-si 31033, Korea; Ginoo76@hanmail.net

3 Department of System Semiconductor Engineering, Sangmyung University, Sangmyeongdae-gil, Cheonan-si 31066, Korea; sungwon@smu.ac.kr

4 National Institute of Agricultural Sciences, 166 Nongsaengmyeong-ro, Wanju 55365, Korea; selenium2012@korea.kr

5 Department of Central Area, National Institute of Crop Science, Rural Development Administration, Suwon-si 16429, Korea

* Correspondence: leeyy260@korea.kr; Tel.: +82-31-290-6766

Citation: Ju, S.; Song, S.; Lee, J.; Hwang, S.; Lee, Y.; Kwon, Y.; Lee, Y. Development of Nano Soy Milk through Sensory Attributes and Consumer Acceptability. Foods 2021, 10, 3014. https://doi.org/10.3390/ foods10123014

Academic Editor:

Jean-Xavier Guinard

Received: 16 October 2021

Accepted: 22 November 2021

Published: 5 December 2021

Publisher's Note: MDPI stays neutral with regard to jurisdictional claims in published maps and institutional affiliations.

Copyright: (c) 2021 by the authors. Licensee MDPI, Basel, Switzerland. This article is an open access article distributed under the terms and conditions of the Creative Commons Attribution (CC BY) license (https:// creativecommons.org/licenses/by/ $4.0 /)$.
Abstract: Nanotechnology is currently applied in food processing and packaging in the food industry. Nano encapsulation techniques could improve sensory perception and nutrient absorption. The purpose of this study was to identify the sensory characteristics and consumer acceptability of three types of commercial and two types of laboratory-developed soy milk. A total of 20 sensory attributes of the five different soy milk samples, including appearance, smell (odor), taste, flavor, and mouthfeel (texture), were developed. The soy milk samples were evaluated by 100 consumers based on their overall acceptance, appearance, color, smell (odor), taste, flavor, mouthfeel (texture), goso flavor (nuttiness), sweetness, repeated use, and recommendation. One-way analysis of variance (ANOVA), principal component analysis (PCA), and partial least square regression (PLSR) were used to perform the statistical analyses. The SM_D sample generally showed the highest scores for overall liking, flavor, taste, mouthfeel, sweetness, repeated consumption, and recommendation among all the consumer samples tested. Consumers preferred sweet, goso (nuttiness), roasted soybean, and cooked soybean (nuttiness) attributes but not grayness, raw soybean flavor, or mouthfeel. Sweetness was closely related to goso (nuttiness) odor and roasted soybean odor and flavor based on partial least square regression (PLSR) analysis. Determination of the sensory attributes and consumer acceptance of soymilk provides insight into consumer needs and desires along with basic data to facilitate the expansion of the consumer market.

Keywords: sensory attributes; consumer acceptability; laboratory-developed soy milks; partial least square regression (PLSR) analysis

\section{Introduction}

Soy milk is a plant beverage with high nutritional value due to the abundance of proteins, fatty acids, and health ingredients, such as isoflavones, oligosaccharides, anthocyanins, and dietary fiber. Many studies have reported the antioxidant, anticancer, antidiabetic, and hypocholesterolemic activities of soy milk in addition to its therapeutic effects against osteoporosis, kidney disease, and high blood pressure [1-6]. Therefore, there has been an increased interest in nutritional aspects and demand for soy products in the beverage industry. In America, sales of soy milk increased dramatically from $\$ 500$ million in 2001 to $\$ 1$ billion in 2008 [7]. Despite the rapid increase in the sales of soy milk, it is purchased by $13 \%$ or fewer households in the USA [8]. Soy-based beverages accounted for $7.7 \%$ of the market share in Korea compared with $22.8 \%$ attributed to fruits and vegetables juice, with coffee drinks accounting for $17.5 \%$, soft drinks for $16.4 \%$, functional 
beverages constituting $11.0 \%$, and mineral water amounting to $10.9 \%$ of the total beverage market in 2012 [9]. Nevertheless, some consumers do not appreciate soymilk because of the raw-beany flavor and the unique taste [10].

Soy bean flavor and nutrients are affected by a number of factors, such as soy bean cultivars, geographic differences, and manufacturing techniques, as well as the soy bean components including proteins, fatty acids, oligosaccharides, and other contents [10-12]. The technology for the improvement of soy bean flavor ensures the retention of key nutrients, which contribute to the popularity of the beverage worldwide. Studies have investigated the analytical and sensory attributes of soy milk, and the consumer test results $[3,6,12-20]$.

However, the relationship between sensory analysis and the effects of processing methods have rarely been reported. Nanotechnology is a rapidly growing area for the manufacture of nanoscale materials. Nanotechnology can be applied to food packaging, food processing, and functional foods to ensure food safety and quality [21]. Nanotechnology in the food industry could currently be applied to protect foods against bacterial deterioration and extend the shelf life of foods [22], increase the bioavailability of bioactive compounds and nutrient absorption [23,24], protect against oxidant ingredients [25,26], and also increase sensory perception [27]. Some studies have shown that nanomaterials by delivery systems improved the bioavailability of bioactive compounds, such as calcium [24], vitamins [28], and iron [29].

Although research on food nanotechnology has yet to be fully clarified, it could affect the sensory perception for improving flavor release and flavor retention by nanoencapsulation techniques [30]. Nanotechnology can be used to improve food characteristics, such as particles and flavor, and foods with nanomaterials show higher production efficiency, better taste, and nutrient absorption [22]. Soy milk products generally have some problems, such as raw-beany flavor and residual aftertaste, even if they have high nutritional values. Therefore, we would like to develop nano soy milk, which could have low beany flavor and residual taste with nano particles using nanotechnology.

This study investigated the descriptive sensory characteristics and consumer acceptance of three commercially available and two laboratory-developed types of soy milk using nanotechnology and analyzed the relationship between descriptive sensory characteristics and consumer acceptability of five types of soy milk. The differences in the sensory attributes and consumer acceptability of soymilk can be used to analyze the consumer needs and desires. Therefore, these results provide basic data for the market expansion of soy milk.

\section{Materials and Methods}

\subsection{Materials}

Five types of soy milk were investigated in this study. The products were named SM_W (Soy Milk_Woori), SM_Y (Soy Milk_Y brand), SM_D (Soy Milk_D brand), SM_N (Soy Milk_Nano), and SM_J (Soy Milk_J brand). Three (SM_Y, SM_D, and SM_J) stable and commercially available products were sugar-free and contained no additives. The other two types of soy milk were synthesized in the laboratory. The soy milk types developed in the laboratory (SM_W and SM_N) were derived from the new soy bean crop (Daechan, Chungja 3, Saedanbaek) grown in 2015 and 2016 by the National Institute of Crop Science of Rural Development Administration in Korea. The Chungja 3 soybean includes additional isoflavone and anthocyanin content, and the Saedanbaek soybean contains a higher protein content compared with the general soybeans. One of the synthetic soy milks (SM_N) was composed of nanoparticles, which increased the digestion and absorption compared with the general soy milk. Table 1 lists the sample names, brands, and ingredients. 
Table 1. Sample information.

\begin{tabular}{|c|c|c|}
\hline Product Abbreviation & Ingredient & Random Sampling Numbers \\
\hline SM_W & $\begin{array}{l}\text { Daechan soybean:Cheongja } 3 \text { soybean:Saedanbaek soybean }=5: 3: 2 \\
\qquad(20 \mathrm{~kg}: 12 \mathrm{~kg}: 8 \mathrm{~kg})\end{array}$ & 185 \\
\hline SM_Y & $\begin{array}{l}\text { Organic soymilk liquid (soybean solid, organic soybean, Australian), } \\
\text { organic blackbean extract (solid, organic black bean, Korean) }\end{array}$ & 257 \\
\hline SM_D & $\begin{array}{l}\text { Soymilk liquid (soybean solid, soybean, Korean), small soybean } \\
\text { powder (Korean), seaweed powder (United Kindom), sun-dried salt } \\
\text { (Korean) }\end{array}$ & 348 \\
\hline SM_N & $\begin{array}{l}\text { Daechan soybean:Cheongja } 3 \text { soybean:Saedanbaek soybean = 5:3:2 } \\
\text { (20 kg:12 kg:8 kg) }\end{array}$ & 415 \\
\hline SM_J & Soybean liquid (soybean solid-imported), salt (Korean) & 536 \\
\hline
\end{tabular}

\subsection{Soy Milk Production and Sample Preparation}

The soy milks in the laboratory were developed from Daechan, Chungja 3, and Saedanbaek crops (20:12:8 = total $40 \mathrm{~kg}$ ) by the Rural Development Administration. The soy milk processing technique is presented in Figure 1. It was produced by soaking the soy beans for $24 \mathrm{~h}$, grinding at $80^{\circ} \mathrm{C}$, and exposure to colloid mills twice by adding water to obtain a crude liquid, which was stirred in a homogenizer (HF-93, SMT Co., Ltd., Tokyo, Japan) at $1000 \times g$ and $75 \sim 78{ }^{\circ} \mathrm{C}$ for $40 \mathrm{~min}$ to obtain the final soy milk. The nanoparticlecontaining soy milk was obtained by stirring liquid for at least $100 \mathrm{~min}$, followed by sonication and evaporation of water in the rotary evaporator for $100 \mathrm{~min}$ or more, followed by vortexing up to three times after centrifugation. The final nanoparticle-containing soy milk was produced after spray drying. The laboratory soy milk was stored in a sanitized plastic bag under refrigeration at $1.7^{\circ} \mathrm{C}$.

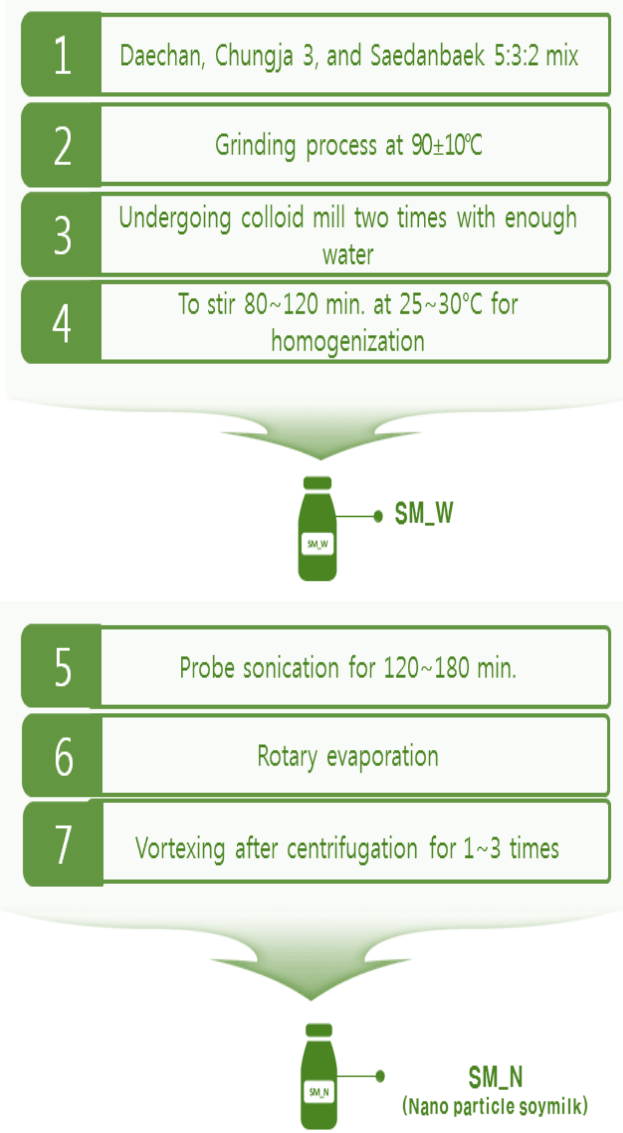

Figure 1. Laboratory soymilk production process. 


\subsection{Sensory Evaluation}

\subsubsection{Sample Preparation}

Soy milks were stored at $4{ }^{\circ} \mathrm{C}$ in a refrigerator and used at the time of experiment. Samples of soy milk $(20 \mathrm{~mL}$ ) were poured into $50 \mathrm{~mL}$ white paper cups, and covered with lids and served at room temperature $\left(20 \pm 5^{\circ} \mathrm{C}\right)$. Panelists were not allowed to eat or drink anything other than water $1 \mathrm{~h}$ prior to the descriptive test. Panelists were instructed to rinse their mouths with spring water before and between each sample. The samples were coded with 3-digit random numbers and presented using a Latin square design to minimize the carry-over effects [23].

The descriptive analysis was conducted in triplicate for 3 days, and each session evaluating the sensory attributes of the five soymilks lasted approximately $1 \mathrm{~h}[13,20]$. A 9-point scale (ranging from ' $1=$ not at all' to ' $9=$ extremely strong') was used. Panelists discussed the ratings of attributes with other panelists. Panelists took a 15-min break between the sample tests (after the first 2 samples were tested) to prevent sensory adaptations. All reference standards were presented at room temperature. Panelists were allowed to retest and change their rating during the evaluation when a panelist failed to remember a reference for a specific attribute. Panelists rated the intensities of one attribute at a time for the entire sample set, rinsed their mouths with spring water between each sample, and moved on to the next attribute to minimize sample variation.

\subsubsection{Panel Selection and Training}

Eight panelists selected from the students of Konkuk University ( 3 males and 5 females, age range 21 24) with previous experience in evaluating soy products were selected according to their interest, availability, and their ability to articulate. The basic screening tests, such as a basic taste test, flavor, and aroma recognition test, and an intensity ranking test were conducted during one week to understand the basics of sensory evaluation by panelists [24].

A quantitative descriptive analysis [25] was used to evaluate the sensory characteristics of the five soy milks. The descriptive analysis included training sessions and primary evaluation. Panelists were trained for a period of 2 weeks in 90-min sessions 3 times a week. Six sessions were devoted to tasting soymilks and group discussion to develop attributes and references. Initially, panelists were exposed to a variety of soymilks including laboratory-developed soymilks as well as commercial brands to obtain an understanding of the basics of sensory evaluation and the procedures. The preliminary sensory characteristics, such as the appearance, smell, taste, flavor, and mouthfeel, were generated after testing a variety of soy milks. In the next session, they were asked to evaluate sensory differences among samples, and then they generated the terms of attributes and selected references by group discussion.

During the third session, the panelists defined descriptive attributes compared with standard references and the final descriptive attributes were confirmed based on a consensus of the standard attributes. The panelists gave ratings based on a 16-point intensity rating scale $(0=$ none; $15=$ extremely strong $)$ in each attribute.

Furthermore, the preliminary intensity test was conducted to accurately rate the standard intensities of each attribute in individual booths. Then, three sessions of individual booth evaluations of panels were completed to collect data for the study. A supplementary training session was held to minimize the differences in intensity rates between the panelists.

\subsubsection{Development of a Soy Milk Lexicon}

The 20 sensory attributes were determined according to appearance, smell/aroma, taste/flavor, and mouthfeel/texture (Table 2). Four descriptors, such as grayness, whiteness, brownness, and roughness, were developed to define the appearance. The aroma/odor was described as sweet, goso (nuttiness), raw soy bean, cooked soy bean, wheat flavor, and roasted soy bean. Sweet and salty terms were used to define taste and milk, whereas raw, cooked, and roasted soybeans indicated flavor. Mouthfeel/texture was defined by cohe- 
siveness, coating, astringent, swallow, and particle features. The definitions and references of the 20 descriptive attributes were also discussed. Table 2 lists the sensory attributes, definitions, and references of soy milks analyzed in this study. Furthermore, a preliminary test of sensory intensity was conducted to rate the relative intensity of the attributes. A few panelists received supplementary training to reduce the deviation of intensity rating.

Table 2. Definition and standard reference of descriptive attributes of soymilk.

\begin{tabular}{|c|c|c|}
\hline Attributes & Definition & Standard Reference \\
\hline \multicolumn{3}{|l|}{ Appearance } \\
\hline Grayness & Intensity of Grayness color & Strong: jongienara 120 colors 115/N5 (Jongienara, Seoul, Korea) (15) ${ }^{(1)}$ \\
\hline Whiteness & Intensity of Whiteness color & Strong: jongienara 120 colors 143Y/NP (Jongienara, Seoul, Korea) (15) \\
\hline Brownness & Intensity of Brownness color & Strong: jongienara 120 colors 1172 YR/Gr (Jongienara, Seoul, Korea) (15) \\
\hline Roughness & Intensity of Roughness & Strong: Powder of mixed grains $20 \mathrm{~g}$ with $100 \mathrm{~mL}$ water (15) \\
\hline \multicolumn{3}{|l|}{ Odor (smell) } \\
\hline Sweet & The smell associated with chocolate milk & Strong: Mixture $50 \mathrm{~mL}$ of chocolate milk with $50 \mathrm{~mL}$ water (15) \\
\hline Goso (nuttiness) & The smell associated with Buckwheat tea & Strong: Buckwheat tea (15) \\
\hline Cooked soybean & The smell associated with cooked soybean & $\begin{array}{l}\text { Strong: } 30 \mathrm{~g} \text { of soybean that had been soaked for } 3 \mathrm{~h} \text {, cooked for } 1 \mathrm{~h} \text {, and } \\
\text { then ground with } 100 \mathrm{~mL} \text { water (15) }\end{array}$ \\
\hline Wheat flour & The smell associated with dough & Strong: Mix the flour $40 \mathrm{~g}$ and water $12.5 \mathrm{~mL}$ water to make dough (15) \\
\hline Roasted soybean & The smell associated with roasted soybean & Strong: Bean flour (15) \\
\hline \multicolumn{3}{|l|}{ Taste/Flavor } \\
\hline Sweetness & Fundamental taste sensation elicited by sugars & $\begin{array}{l}\text { Normal: } 1.25 \% \text { sucrose solution in spring water }(8) \\
\text { Strong: } 2.5 \% \text { sucrose solution in spring water }(15)\end{array}$ \\
\hline Salty & Fundamental taste sensation elicited by salts & $\begin{array}{l}\text { Normal: } 0.15 \% \mathrm{NaCl} \text { solution in spring water }(8)(2) \\
\text { Strong: } 0.3 \% \mathrm{NaCl} \text { solution in spring water }(15)\end{array}$ \\
\hline Milk & Fundamental flavor sensation elicited by milks & Strong: Seoul milk (15) \\
\hline Cooked soybean & $\begin{array}{l}\text { Fundamental flavor sensation elicited by } \\
\text { cooked soybean }\end{array}$ & $\begin{array}{l}\text { Strong: } 30 \mathrm{~g} \text { of soybean that had been soaked for } 3 \mathrm{~h} \text {, cooked for } 1 \mathrm{~h} \text {, and } \\
\text { then ground with } 100 \mathrm{~mL} \text { water (15) }\end{array}$ \\
\hline Raw soybean & $\begin{array}{l}\text { Fundamental flavor sensation elicited by } \\
\text { raw soybean }\end{array}$ & $\begin{array}{l}\text { Strong: Mixture of ground soybean ( } 30 \mathrm{~g} \text { soaked for } 3 \mathrm{~h} \text { and ground with } \\
100 \mathrm{~mL} \text { water) (15) }\end{array}$ \\
\hline Roasted soybean & $\begin{array}{l}\text { Fundamental flavor sensation elicited by } \\
\text { roasted soybean }\end{array}$ & Strong: Bean flour (15) \\
\hline \multicolumn{3}{|l|}{ Mouthfeel/Texture } \\
\hline Cohesiveness & Degree to which liquid is viscous or thick & Normal: chocolate milk (Gana Milk) (8) \\
\hline Coating & Degree to film coating the tongue & Normal: Seoul milk (8) \\
\hline Astringency & Dryness perceived in the mouth & Strong: Mixture $15 \mathrm{~g}$ of green tea with $1 \mathrm{~L}$ water (15) \\
\hline Swallowing & Degree to which water swallow in mouth & Strong: Soybean oil (15) \\
\hline Particles & Degree to which particles of liquid & Normal: Powder of mixed grains (8) \\
\hline
\end{tabular}

\subsubsection{Consumer Acceptance Test}

The consumers ( $n=100$, females: 54 , males: 46 , age: 20 26) were recruited from the students enrolled at Konkuk University. The consumer test also conducted the same test condition as the descriptive test. Samples of soy milk $(20 \mathrm{~mL})$ were poured into $50 \mathrm{~mL}$ white paper cups, and covered with lids and served at room temperature $\left(20 \pm 5^{\circ} \mathrm{C}\right)$. The consumer test questionnaire included general characteristics about consumer panelists, overall acceptability, appearance acceptability, color acceptability, flavor acceptability, taste acceptability, mouthfeel acceptability, goso (nuttiness), sweet, repeated use, and recommendations to others. Consumers rated their liking using a nine-point hedonic scale (ranging from 1 (suggesting intense dislike) to 9 (indicating intense like)) [15]. The consumers rinsed their mouth with water between samples to avoid residual effects. 
The five samples coded with a 3-digit random number were randomly presented to the consumers using a Williams Latin square design [23].

\subsection{Statistical Analysis}

All statistical analyses were performed using SPSS (Statistical Package for Social Science, ver. 25.0, Chicago, IL, USA) and SAS (ver. 9.4, SAS Institute, Cary, NC, USA). To determine the significant differences in sensory attributes between the samples, a oneway analysis of variance (ANOVA) was performed. Duncan's multiple range test was conducted as a post hoc comparison $(a=0.05)$. Principal component analysis (PCA) was conducted to identify sensory attributes and samples. In addition, partial least square regression (PLSR) analysis was conducted to correlate samples, descriptive attributes, and consumer acceptability.

\section{Results and Discussion}

\subsection{Descriptive Analysis}

Table 3 shows the mean intensity of 20 sensory attributes for 5 soy milk samples. The 20 sensory attributes except for the coating attribute varied significantly among the samples $(p<0.001)$. Based on sample appearance, the SM_Y commercial sample showed the maximum whiteness, whereas SM_D and SM_J showed the highest scores of brownness and grayness, respectively $(p<0.001)$. In terms of odor attributes, SM_D showed the highest score for sweetness, and SM_W scored the highest value for goso flavor (nuttiness) and cooked soy bean odor among the five types of soy milk $(p<0.001)$. Hwang and Hong [20] analyzed the sensory components of goso flavor (nuttiness) via descriptive analysis and consumer tests of 10 commercial types of soy milk. The results indicated that goso flavor (nuttiness) was positively correlated with cooked soy bean characteristics. A highly positive correlation existed between goso (nuttiness) and cooked soy bean attributes. With regard to taste and flavor attributes, the SM_J sample exhibited the lowest sweetness and the highest saltiness, and raw soybean flavor among five samples. In contrast, it yielded the lowest scores for cooked soybean and roasted soybean flavor among them $(p<0.001)$. SM_Y showed the lowest particle and the highest swallow of mouthfeel among the samples, which may be closely related to the highest degree of whiteness in the SM_Y sample. The SM_Y sample included very fine soybean solid particles compared with those of other types of soy milk. Several studies analyzed and investigated the descriptive attributes of soy milk. The descriptive sensory attributes of soymilk have been investigated by Torres-Penaranda and Reitmeier [13], Day N'Kouka et al. [3], and Rho et al. [25]. Torres-Penaranda and Reitmeier [13] presented 12 descriptive attributes based on commercial soymilk and soymilk processed from normal, lipoxygenase-free soybeans, and lipoxygenase-free soybeans stored for 15 months. The 12 descriptive attributes were 'beany' (raw as hexanal), 'starch as flour', and 'sweet' as dairy caramelized for aroma; 'beany', 'grassy', 'sweet as green floral', 'painty', 'sweet as dairy caramelized', 'metallic', and 'bitter' for flavor; and 'astringent' and 'mouth coating' for mouthfeel. Day N'Kouka et al. [3] developed 31 sensory terms of five commercial soymilks and 1 laboratory-prepared soymilk. The descriptive sensory terms included terms, such as cooked soy, green, nutty, roasted soy, caramel, malty, vanilla, and sweetness. Rho et al. [27] also reported 28 descriptive sensory attributes of 9 commercial soymilks. They developed the 28 descriptive attributes, which included 'grayness', 'yellowness', 'clearness', and 'milky' appearance; 'opaque', sweet', 'cooked chestnut', 'cooked soybean', and 'beany' odor; 'mild', 'salty', 'sour', 'sweet', 'bitter', 'greasy', 'savory', 'metallic', 'goso (nuttiness)', 'nutty', 'cooked chestnut', 'cooked soybean', and 'raw soybean' flavor and taste; 'coarse of particle', 'consistency', 'lubricity', and 'astringent' mouthfeel; and 'residual sensation' and 'coated' after sensation. SM_N had high scores of cohesiveness and coating mouthfeel and lower swallowness mouthfeel than others. These results could be related with the encapsulation technique of the nanotechnique. 
Table 3. Intensities of the descriptive attributes for five soymilks.

\begin{tabular}{|c|c|c|c|c|c|c|c|c|}
\hline & SM_W & SM_Y & SM_D & SM_N & SM_J & Sample & $\begin{array}{c}p \text {-Value } \\
\text { Panel }\end{array}$ & $\mathbf{S} \times \mathbf{P}^{(2)}$ \\
\hline \multicolumn{9}{|l|}{ Appearance } \\
\hline Whiteness_A & $7.67 \pm 2.25^{\mathrm{b},(3)}$ & $12.70 \pm 1.54^{\mathrm{a}}$ & $1.85 \pm 1.32^{\mathrm{c}}$ & $7.26 \pm 2.19^{b}$ & $1.11 \pm 0.58^{\mathrm{c}}$ & $<0.001$ & $<0.001$ & 0.866 \\
\hline Browness_A & $4.85 \pm 2.41^{\mathrm{b}}$ & $1.85 \pm 1.17^{\mathrm{c}}$ & $14.37 \pm 0.88^{a}$ & $5.59 \pm 2.68^{b}$ & $1.37 \pm 1.21^{\mathrm{c}}$ & $<0.001$ & 0.104 & 0.980 \\
\hline Grayness_A & $3.48 \pm 1.65^{\mathrm{b}}$ & $1.33 \pm 0.48^{c}$ & $1.67 \pm 2.32^{\mathrm{c}}$ & $4.11 \pm 2.08^{a}$ & $14.59 \pm 0.98^{a}$ & $<0.001$ & 0.053 & 0.906 \\
\hline Roughness_A & $12.93 \pm 2.38^{a b}$ & $1.48 \pm 1.55^{\mathrm{d}}$ & $12.22 \pm 2.49^{b}$ & $13.52 \pm 1.83^{\mathrm{a}}$ & $6.33 \pm 2.54^{c}$ & $<0.001$ & 0.034 & 0.014 \\
\hline \multicolumn{9}{|l|}{ Odor (smell) } \\
\hline Sweet_O & $4.96 \pm 2.86^{b}$ & $3.07 \pm 1.52^{c}$ & $11.44 \pm 1.74^{\mathrm{a}}$ & $4.81 \pm 2.59^{b}$ & $2.00 \pm 1.96^{c}$ & $<0.001$ & 0.347 & 0.216 \\
\hline Goso (nuttiness)_O & $10.00 \pm 2.73^{a}$ & $4.48 \pm 2.17^{\mathrm{d}}$ & $8.41 \pm 2.68^{b}$ & $6.56 \pm 3.12^{c}$ & $2.00 \pm 1.94 \mathrm{e}^{\mathrm{e}}$ & $<0.001$ & 0.808 & 0.981 \\
\hline Cooked soybean_O & $13.04 \pm 1.74^{\mathrm{a}}$ & $7.89 \pm 2.90^{\mathrm{c}}$ & $5.48 \pm 2.89^{d}$ & $10.52 \pm 2.52^{b}$ & $3.19 \pm 2.53^{\mathrm{e}}$ & $<0.001$ & 0.745 & 0.525 \\
\hline Wheat flour_O & $7.63 \pm 2.10^{b}$ & $10.96 \pm 3.02^{\mathrm{a}}$ & $4.96 \pm 2.26^{c}$ & $7.15 \pm 2.35^{b}$ & $3.78 \pm 3.19^{c}$ & $<0.001$ & 0.578 & 0.059 \\
\hline $\begin{array}{c}\text { Roasted } \\
\text { soybean_O }\end{array}$ & $7.15 \pm 2.03^{b}$ & $2.63 \pm 1.60^{\mathrm{c}}$ & $8.78 \pm 3.20^{a}$ & $7.26 \pm 1.79^{b}$ & $2.04 \pm 1.32^{c}$ & $<0.001$ & 0.481 & 0.267 \\
\hline \multicolumn{9}{|l|}{ Taste/Flavor } \\
\hline Sweetness_T & $7.70 \pm 2.05^{\mathrm{a}}$ & $5.37 \pm 2.62^{b}$ & $7.56 \pm 2.64^{\mathrm{a}}$ & $5.56 \pm 2.03^{b}$ & $2.41 \pm 1.67^{c}$ & $<0.001$ & 0.022 & 0.013 \\
\hline Salty_T & $4.74 \pm 1.53^{c}$ & $2.70 \pm 2.52^{d}$ & $9.33 \pm 2.47^{b}$ & $5.22 \pm 2.17^{c}$ & $12.30 \pm 1.94^{\mathrm{a}}$ & $<0.001$ & $<0.001$ & 0.084 \\
\hline Milk_F & $7.52 \pm 2.06^{b}$ & $9.22 \pm 2.72^{\mathrm{a}}$ & $8.85 \pm 2.43^{a}$ & $7.41 \pm 2.04^{b}$ & $4.15 \pm 2.49^{c}$ & $<0.001$ & 0.490 & 0.441 \\
\hline Raw soybean_F & $5.19 \pm 1.96^{b}$ & $3.74 \pm 3.18^{c}$ & $3.52 \pm 1.45^{c}$ & $5.30 \pm 2.15^{b}$ & $6.67 \pm 1.62^{\mathrm{a}}$ & $<0.001$ & 0.011 & 0.055 \\
\hline Cooked soybean_F & $10.56 \pm 2.21^{a}$ & $10.74 \pm 3.21^{\mathrm{a}}$ & $5.93 \pm 1.94^{b}$ & $10.19 \pm 2.39^{a}$ & $4.11 \pm 1.67^{c}$ & $<0.001$ & 0.009 & 0.024 \\
\hline Roasted soybean_F & $9.04 \pm 2.58^{\mathrm{a}}$ & $3.15 \pm 1.70^{\mathrm{b}}$ & $8.70 \pm 2.52^{\mathrm{a}}$ & $8.41 \pm 2.55^{\mathrm{a}}$ & $2.89 \pm 1.45^{b}$ & $<0.001$ & 0.911 & 0.330 \\
\hline \multicolumn{9}{|l|}{ Mouthfeel/Texture } \\
\hline Cohesiveness_M & $9.81 \pm 2.34 \mathrm{ab}$ & $6.59 \pm 1.53^{c}$ & $9.89 \pm 1.48^{\mathrm{ab}}$ & $10.70 \pm 2.52^{\mathrm{a}}$ & $9.44 \pm 1.25^{b}$ & $<0.001$ & 0.210 & 0.195 \\
\hline Coating_M & $9.33 \pm 2.22$ & $9.04 \pm 1.26$ & $8.78 \pm 2.21$ & $9.48 \pm 2.14$ & $9.78 \pm 1.95$ & 0.336 & 0.006 & 0.461 \\
\hline Swallowness_M & $3.96 \pm 1.34^{d}$ & $11.37 \pm 1.52^{\mathrm{a}}$ & $6.89 \pm 1.65^{c}$ & $3.78 \pm 1.05^{\mathrm{d}}$ & $9.30 \pm 2.16^{b}$ & $<0.001$ & 0.002 & 0.347 \\
\hline Particle_M & $10.74 \pm 2.07^{a}$ & $1.59 \pm 0.89^{\mathrm{d}}$ & $7.26 \pm 1.79^{b}$ & $11.44 \pm 1.69^{a}$ & $3.81 \pm 1.98^{c}$ & $<0.001$ & 0.002 & 0.841 \\
\hline Astringency_M & $9.78 \pm 1.91^{\mathrm{a}}$ & $2.19 \pm 1.18^{\mathrm{d}}$ & $7.81 \pm 1.94^{\mathrm{b}}$ & $9.93 \pm 1.90^{\mathrm{a}}$ & $4.56 \pm 1.87^{c}$ & $<0.001$ & $<0.001$ & 0.529 \\
\hline
\end{tabular}

(1) $p$-value by ANOVA, ${ }^{(2)}$ The value of $\mathrm{S} \times \mathrm{P}$ means the $p$-value by two-way ANOVA by the interaction between Sample and Panel.

(3) Mean \pm Standard Deviation, ${ }^{\text {a-e }}$ Means values within the same row with the same alphabet superscripts do not differ significantly $(p<0.05)$.

\subsection{Principal Component Analysis of Soy Milk}

PCA was used to identify the relationship between the descriptive attributes and the samples in Figure 2. The PCA biplot represented $80.52 \%$ of the total variation with $44.24 \%$ (PC 1) and $36.27 \%$ (PC 2). The right side of PC 1 was associated with cooked soybean, sweet, roasted soybean, goso flavor (nuttiness), particle, astringent, and browny sensory attributes, and the SM_W, SM_N, and SM_D soymilk samples were closely related to those attributes. SM_W and SM_N showed similar sensory attributes because they were synthesized in the laboratory using the same ingredients. The negative side showed that raw soybean, coating, grayness, and salty attributes were related to the SM_J sample. Wheat flour and whiteness were located on the positive side of PC 2 and were closely associated with the SM_Y sample.

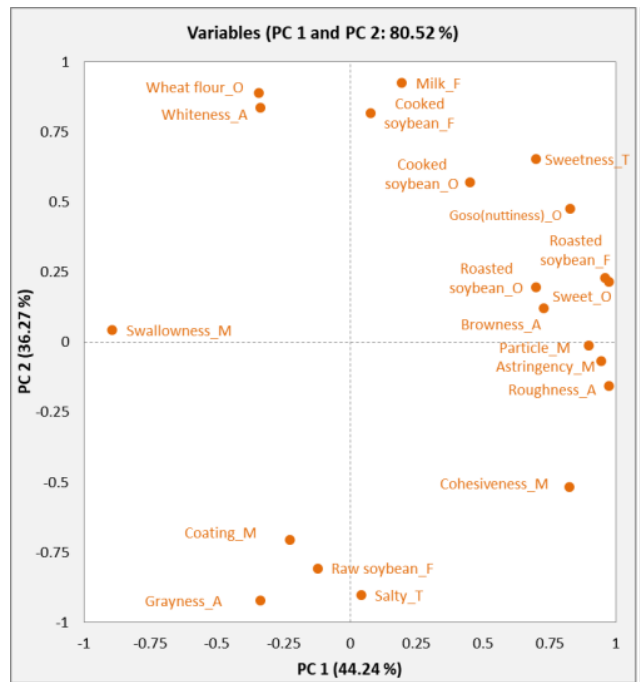

(a)

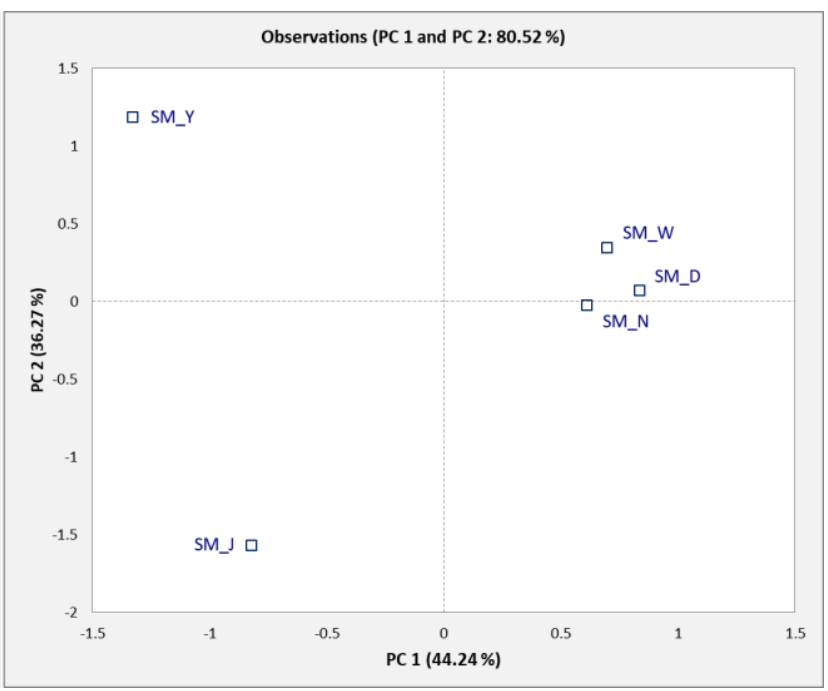

(b)

Figure 2. Principal component (PC) loadings and scores of the attributes (a) and five soymilk samples (b). 


\subsection{Consumer Acceptance}

Table 4 presents the results of the consumer acceptability of the five soy milk samples. All soy milk samples were evaluated by 100 consumers based on the overall liking, appearance acceptability, color acceptability, flavor liking, taste acceptability, mouthfeel acceptability, goso flavor (nuttiness), sweet, repeated use, and recommendation. All attributes were not significantly different $(p<0.05)$. However, the SM_D sample generally showed the highest scores for the overall liking, flavor, taste, mouthfeel, sweet, repeated use, and recommendation. The synthetic SM_W displayed the highest score with regard to appearance among the samples. Otherwise, SM_N showed the highest color score based on nanotechnology.

Table 4. Consumer acceptability of five soymilks.

\begin{tabular}{|c|c|c|c|c|c|c|}
\hline & SM_W & SM_Y & SM_D & SM_N & SM_J & $p$-Value ${ }^{(1)}$ \\
\hline Overall_liking & $4.23 \pm 2.19^{(2)}$ & $4.13 \pm 2.31$ & $4.34 \pm 2.06$ & $4.13 \pm 1.83$ & $2.91 \pm 1.93$ & 0.544 \\
\hline Appearance_liking & $5.59 \pm 1.74$ & $5.50 \pm 2.41$ & $4.47 \pm 1.83$ & $5.27 \pm 1.80$ & $4.32 \pm 2.32$ & 0.306 \\
\hline Color_liking & $5.72 \pm 1.91$ & $5.69 \pm 2.42$ & $4.52 \pm 1.93$ & $6.06 \pm 6.06$ & $4.29 \pm 2.31$ & 0.463 \\
\hline Flavor_liking & $4.18 \pm 2.22$ & $4.72 \pm 2.16$ & $5.38 \pm 2.22$ & $4.51 \pm 2.05$ & $3.30 \pm 1.77$ & 0.086 \\
\hline Taste_liking & $3.16 \pm 1.84$ & $3.05 \pm 1.85$ & $4.05 \pm 2.14$ & $3.21 \pm 1.80$ & $2.47 \pm 1.90$ & 0.584 \\
\hline Mouthfeel_liking & $3.97 \pm 1.85$ & $4.42 \pm 2.21$ & $4.47 \pm 1.89$ & $3.79 \pm 1.80$ & $3.65 \pm 2.01$ & 0.089 \\
\hline Goso_liking & $4.11 \pm 2.16$ & $3.72 \pm 2.03$ & $4.91 \pm 1.82$ & $4.20 \pm 1.84$ & $3.41 \pm 2.13$ & 0.121 \\
\hline Sweet_liking & $2.95 \pm 1.76$ & $2.90 \pm 1.87$ & $3.39 \pm 2.03$ & $2.86 \pm 1.74$ & $2.45 \pm 1.59$ & 0.057 \\
\hline Try again & $3.04 \pm 2.03$ & $2.81 \pm 1.95$ & $3.16 \pm 2.04$ & $2.97 \pm 1.88$ & $2.08 \pm 1.41$ & 0.235 \\
\hline Recommend & $3.13 \pm 1.98$ & $3.06 \pm 1.97$ & $3.46 \pm 2.04$ & $3.05 \pm 1.77$ & $2.40 \pm 1.68$ & 0.166 \\
\hline
\end{tabular}

(1) $p$-value by One-way ANOVA, (2) Mean \pm Standard Deviation.

Lee et al. [28] investigated the relationship between nutritional composition and soy milk palatability using nine soybean cultivars, including Daechan, Chungja 3, and Saedanbaek. The Daechan cultivar, which was an ingredient of the laboratory-made soy milk, had the highest overall palatability score. Our test samples of soy milk were developed without the addition of sweet components because we wanted to focus on the attributes of soy bean itself. Additionally, the other three commercial soy milks were also prepared as unsweetened ones. Therefore, the low average scores of the consumer tests may be closely related to the unsweetened soy milk samples. Several studies were used to analyze the soy milk regarding consumer interest $[12,14,15,18,19]$. A few such studies indicated that sweet-tasting soy milk topped consumer liking $[12,18]$. Vanilla flavor was also another preferred attribute among consumers reported in Villegas et al. [12] and Nti and Larweh [14]. Nti and Larweh [14] analyzed a consumer test of soy milk in Ghana and found that the addition of flavors, such as vanilla, banana, coffee, or chocolate, improved the consumer acceptability of soy milk. These studies found that consumers generally preferred a darker color, higher viscosity, sweet taste, and increased vanilla flavor.

\subsection{Relationship between Descriptive Attributes and Consumer Acceptability of Soy Milk}

PLSR analysis was used to investigate the relationship between the descriptive attributes and consumer acceptability of the samples. Figure 3 shows the correlation between sensory attributes, consumer acceptability, and soy milk samples. The SM_W, SM_D, and SM_N samples were closely correlated with cooked soybean, goso flavor (nuttiness), sweet, browny texture, roasted soybean, particle, and astringent properties. These samples were also associated with the overall liking, sweet, color, flavor, taste, goso (nuttiness), repeated use, and positive recommendations. The results of this study showed that consumers preferred sweet, goso (nuttiness), roasted soybean, and cooked soybean attributes of soymilk, and sweetness was closely related with goso (nuttiness) and roasted soybean odor and flavor. The findings of this study are consistent with the study of Hwang and Hong [20], who also reported a positive relationship between goso (nuttiness) and sweet attributes of soy milk in consumer tests. SM_J was related to grayness, raw soybean, and coating 
attributes, which were located on the negative side of PLS 2. Based on consumer acceptability, SM_J scored the lowest in sensory attributes, suggesting that consumers dislike attributes of grayness, raw soybean flavor, and coating mouthfeel. Lawrence et al. [29] investigated the sensory attributes driving the interest in unflavored soymilks among different U.S. consumers, using descriptive analysis and consumer tests. They found that the least-liked sensory attributes were beany, green/grassy, and meaty/brothy flavors; bitter taste; and astringency. The SM_Y soy milk sample was associated with the odor of wheat flour and whiteness.

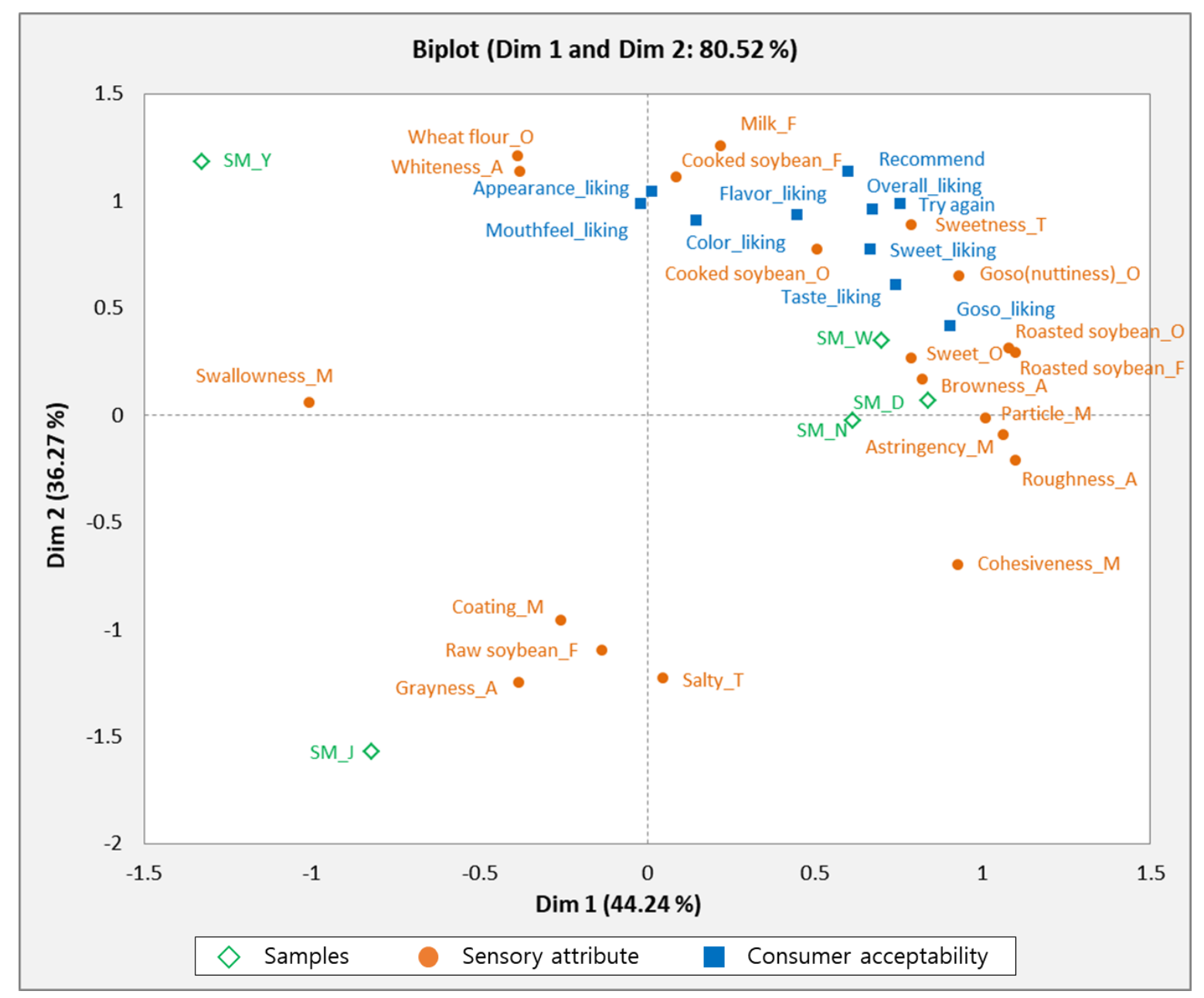

Figure 3. PLSR result from relationship between sensory attributes of five soymilks and consumer acceptability.

\section{Conclusions}

This study was conducted to identify the descriptive sensory characteristics and consumer acceptability of three commercial and two laboratory-developed soy milks, and analyzed the correlation between descriptive sensory characteristics and consumer acceptance of five soymilks. The descriptive analysis was conducted with eight trained panels. The 20 sensory attributes were determined according to appearance (grayness, whiteness, brownness, and roughness), smell (sweet, goso, raw soybean, cooked soybean, wheat flavor, and roasted soybean), taste (sweet, salty), flavor (milk, raw soybean, cooked soybean, and roasted soybean), and mouthfeel (cohesiveness, coating, astringent, swallow, and particles). Consumer acceptance was tested with 100 consumers and all attributes were not significantly different $(p<0.05)$. However, the SM_D sample generally showed the highest scores of overall liking, flavor, taste, mouthfeel, sweet, repeated use, and recommendation among all samples. Based on PLSR analysis, the SM_W, SM_D, and SM_N samples were closely related to cooked soybean, goso flavor (nuttiness), sweetness, 
browny texture, roasted soybean, particle, and astringent properties, and also correlated with overall liking, sweetness, color, flavor, taste, goso flavor (nuttiness), repeated use, and recommendation to others.

Overall, this study did not clearly show that the nano soy bean milk has improved sensory qualities compared to commercial ones. However, it presents the potential for the application of nanotechnology in soy milk development. The application of nanotechnology in the food industry remains a challenge because future studies provide guidance and rules regarding the public health benefits and risks for food nanotechnology. These results can be used as basic data for the application of the functionality of food nanotechnology and to expand the consumer market of soy milk.

Author Contributions: Conceptualization, Y.K. and S.J.; methodology, Y.K., S.J.; software, Y.K. and S.J.; validation, Y.L. (Yuyoung Lee) and Y.L. (Yoonmi Lee); formal analysis, Y.L. (Yuyoung Lee) and S.J.; investigation, Y.L. (Yuyoung Lee), S.S. and J.L.; data curation, S.H., Y.L. (Yuyoung Lee) and J.L.; writing-original draft preparation, S.S. and S.J.; writing-review and editing, Y.L. (Yuyoung Lee) and S.J.; visualization, S.H. and Y.L. (Yuyoung Lee); supervision, Y.L. (Yuyoung Lee) and S.J.; project administration, Y.L. (Yuyoung Lee) All authors have read and agreed to the published version of the manuscript.

Funding: This research was funded by the Cooperative Research Program for Agriculture Science \& Technology Development (PJ01188501, PJ01188502 and PJ01188503), the Rural Development Administration, the Republic of Korea.

Institutional Review Board Statement: The study was conducted according to the guidelines of the Declaration of Helsinki, and reviewed and approved by Konkuk University Institutional Review Board (IRB approval number: 7001355-202001-E-122).

Informed Consent Statement: Informed consent was obtained from all subjects involved in the study.

Conflicts of Interest: The authors declare no conflict of interest.

\section{References}

1. Erdman, J.W., Jr. Soy protein and cardiovascular disease: A statement for healthcare professionals from the nutrition committee of the AHA. Circulation 2000, 102, 2555-2559. [CrossRef] [PubMed]

2. Messina, M.J.; Loprinzi, C.L. Soy for Breast Cancer Survivors: A Critical Review of the Literature. J. Nutr. 2001, 131, 3095S-3108S. [CrossRef] [PubMed]

3. Day N'kouka, K.; Klein, B.P.; Lee, S.Y. Developing a lexicon for descriptive analysis of soymilks. J. Food Sci. 2004, 69, 259-263. [CrossRef]

4. Ma, Y.; Huang, H. Characterisation and comparison of phenols, flavonoids and isoflavones of soymilk and their correlations with antioxidant activity. Int. J. Food Sci. Technol. 2014, 49, 2290-2298. [CrossRef]

5. Shin, H.C.; Seong, H.S.; Sohn, H.S. The industrial development and health benefits of the soymilk. Korea Soybean Dig. 2004, 21, 15-27.

6. Yu, H.H. Quality Characteristics and Antioxidant Activity of Soymilk Added with Nelumbo Nucifera Root Powder. Korean J. Hum. Ecol. 2016, 25, 239. [CrossRef]

7. Suppavorasatit, I.; Lee, S.Y.; Cadwallader, K.R. Effect of enzymatic protein deamination on protein solubility and flavor binding properties of soymilk. J. Food Sci. 2013, 78, C1-C7. [CrossRef]

8. Dharmasena, S.; Capps, O., Jr. Unraveling demand for dairy-alternative beverages in the United States: The case of soymilk. Agric. Res. Econ. Rev. 2014, 4, 140-157. [CrossRef]

9. Korea Agro-Fisheries \& Food Trade Corporation. The Trend of Beverage Production. Available online: http://www.kati.net/ view / view.do?menuCode=894\&bbsid=1 (accessed on 25 January 2019).

10. Ma, L.; Li, B.; Han, F.; Yan, S.; Wang, L.; Sun, J. Evaluation of the chemical quality traits of soybean seeds, as related to sensory attributes of soymilk. Food Chem. 2015, 173, 694-701. [CrossRef]

11. Min, S.; Yu, Y.; Yoo, S.; Martin, S.S. Effect of Soybean Varieties and Growing Locations on the Flavor of Soymilk. J. Food Sci. 2005, 70, C1-C11. [CrossRef]

12. Terhaag, M.M.; Almeida, M.B.; Benassi, M.D.T. Soymilk plain beverages: Correlation between acceptability and physical and chemical characteristics. Food Sci. Technol. 2013, 33, 387-394. [CrossRef]

13. Torres-Penaranda, A.; Reitmeier, C. Sensory Descriptive Analysis of Soymilk. J. Food Sci. 2001, 66, 352-356. [CrossRef]

14. Nti, C.A.; Larweh, P.M. Production and sensory characteristics of flavoured soymilk samples. Int. J. Consum. Stud. 2003, 27, 181-184. [CrossRef] 
15. Hinze, A.; Karg, C.; van Zyl, M.; Mohamed, N.; Steyn, N.P. The acceptability of different types of soymilks available in Cape Town in consumers from high and low socio-economic areas. Int. J. Consum. Stud. 2004, 28, 40-48. [CrossRef]

16. Chambers, E.; Jenkins, A.; Mcguire, B.H. Flavor properties of plain soymilk. J. Sens. Stud. 2006, 21, 165-179. [CrossRef]

17. Russell, T.; Drake, M.; Gerard, P. Sensory Properties of Whey and Soy Proteins. J. Food Sci. 2006, 71, S447-S455. [CrossRef]

18. Villegas, B.; Carbonell, I.; Costell, E. Acceptability of Milk and Soymilk Vanilla Beverages: Demographics Consumption Frequency and Sensory Aspects. Food Sci. Technol. Int. 2009, 15, 203-210. [CrossRef]

19. Palacios, O.M.; Badran, J.; Spence, L.; Drake, M.A.; Reisner, M.; Moskowitz, H.R. Measuring Acceptance of Milk and Milk Substitutes Among Younger and Older Children. J. Food Sci. 2010, 75, S522-S526. [CrossRef]

20. Hwang, S.-H.; Hong, J.-H. Sensory drivers of goso flavor in soymilk: Understanding a complex traditional Korean sensory attribute. Food Qual. Prefer. 2013, 29, 113-125. [CrossRef]

21. Srinivas, P.R.; Philbert, M.; Vu, T.Q.; Huang, Q.; Kokini, J.L.; Saos, E.; Chen, H.; Peterson, C.M.; Friedl, K.E.; McDade-Ngutter, C.; et al. Nanotech-nology Research: Applications in Nutritional Sciences. J. Nutr. 2010, 140, 119-124. [CrossRef] [PubMed]

22. De Azeredo HMC. Antimicrobial nanostructures in food packaging. Trends Food Sci. Technol. 2013, 30, 56-69. [CrossRef]

23. Salvia-Trujillo, L.; Martín-Belloso, O.; McClements, D.J. Excipient nanoemulsions for improving oral bioavailability of bioactives. Nanomaterials 2016, 6, 17. [CrossRef]

24. Kim, M.-K.; Lee, J.-A.; Jo, M.-R.; Kim, M.-K.; Kim, H.-M.; Oh, J.-M.; Song, N.W.; Choi, S.-J. Cytotoxicity, Uptake Behaviors, and Oral Absorption of Food Grade Calcium Carbonate Nanomaterials. Nanomaterials 2015, 5, 1938-1954. [CrossRef]

25. Pool, H.; Quintanar, D.; De Dios, F.J.; Mano, C.M.; Bechara, J.E.H.; Godínez, L.A.; Mendoza, S. Antioxidant effects of quercetin and catechin encapsulated into PLGA nanoparticles. J. Nanomater. 2012, 2012, 145380. [CrossRef]

26. Rojas-Grau, M.A.; Soliva-Fortuny, R.; Martín-Belloso, O. Edible coatings to incorporate active ingredients to freshcut fruits: A review. Trends Food Sci. Technol. 2009, 20, 438-447. [CrossRef]

27. Dekkers, S.; Krystek, P.; Peters, R.J.B.; Lankveld, D.P.K.; Bokkers, B.G.H.; Van Hoeven-Arentzen, P.H.; Bouwmeester, H.; Oomen, A.G. Presence and risks of nanosilica in food products. Nanotoxicology 2010, 5, 393-405. [CrossRef]

28. Wajda, R.; Zirkel, J.; Schaffer, T. Increase of Bioavailability of Coenzyme Q10 and Vitamin E. J. Med. Food 2007, 10, 731-734. [CrossRef] [PubMed]

29. Pereira, D.I.; Bruggraber, S.F.; Faria, N.; Poots, L.K.; Tagmount, M.A.; Aslam, M.F.; Frazer, D.; Vulpe, C.; Anderson, G.; Powell, J.J Nanoparticulate iron(III) oxo-hydroxide delivers safe iron that is well absorbed and utilised in humans. Nanomed. Nanotechnol. Biol. Med. 2014, 10, 1877-1886. [CrossRef]

30. Nakagawa, K. Nano- and Microencapsulation of Flavor in Food Systems. In Nano- and Microencapsulation for Foods; Chapter 10; Kwak, H.-S., Ed.; John Wiley \& Sons: Oxford, UK, 2014; pp. 249-272. 